\title{
PENGARUH AKTIVITAS FISIK INTENSITAS SEDANG TERHADAP PENURUNAN KADAR GLUKOSA DARAH SEWAKTU PADA LAKI-LAKI OBESITAS
}

\author{
Dian Syafitri* ${ }^{*}$, Khairun Nisa Berawi* \\ *Fakultas Kedokteran, Universitas Lampung \\ $\diamond$ Corresponding Outhor: diansyafitri384@gmail.com
}

\begin{abstract}
Peningkatan prevalensi obesitas berbanding lurus dengan risiko penyakit penyerta (komorbid) yang disebabkan oleh obesitas seperti diabetes melitus (DM) tipe 2 yang terjadi melalui mekanisme resistensi insulin. Jenis penelitian analitik komparatif numerik berpasangan dengan desain quasi experimental dan metode pengambilan data pengukuran berulang (pre test - post test design) dengan kelompok kontrol. Jumlah sampel sebanyak 30 orang, terbagi menjadi kelompok kontrol positif (K1) terdiri atas 10 orang obesitas grade II (indeks masa tubuh $\geq 30 \mathrm{~kg} / \mathrm{m}^{2}$ ), kelompok kontrol negatif (K2) terdiri atas 10 orang normal (indeks masa tubuh $18,55-22,99 \mathrm{~kg} / \mathrm{m}^{2}$ ) dan kelompok perlakuan $(\mathrm{P})$ terdiri atas 10 orang obesitas grade II (indeks masa tubuh $\geq 30 \mathrm{~kg} / \mathrm{m}^{2}$ ) yang diberikan perlakuan aktivitas fisik intensitas sedang berupa berjalan cepat selama 30 menit atau setara dengan HRmax 55-70 persen.Analisis menggunakan Paired T-Test untuk melihat perbedaan pretest dan posttest menunjukkan nilai $\mathrm{p}=0,087$ pada kelompok $\mathrm{P} 1, \mathrm{p}=0,058$ pada kelompok P2 dan $\mathrm{p}=0,000$ pada kelompok P. Analis menggunakan One Way Anova untuk melihat perbedaan antar kelompok menunjukkan nilai $\mathrm{p}=0,002$ antara $\mathrm{P}$ dan $\mathrm{K} 1, \mathrm{p}=0,085$ antara kelompok $\mathrm{P}$ dan $\mathrm{K} 2, \mathrm{p}=0,474$ antara kelompok K1 dan K2. Terdapat pengaruh yang signifikan secara statistik aktivitas fisik intensitas sedang berupa berjalan cepat selama 30 menit terhadap kadar glukosa darah sewaktu pada laki-laki obesitas
\end{abstract}

Kata Kunci: Aktivitas fisik intensitas sedang, glukosa darah, obesitas.

\section{LATAR BELAKANG}

Obesitas adalah keadaan akumulasi lemak berlebih pada jaringan adiposa tubuh yang dapat menyebabkan gangguan kesehatan (WHO, 2018). Obesitas merupakan permasalahan yang menjadi perhatian dunia karena prevalensinya yang terus meningkat di dunia, di Indonesia dan di Provinsi Lampung berdasarkan Riset Kesehatan Dasar tahun 2018 (Riskesdas, 2018). Obesitas terjadi karena ketidakseimbangan antara intake kalori dan pengeluaran kalori (Ercho, Berawi, Susatiningsih, 2013). Ketidakseimbangan ini dipicu oleh berkembangnya pola hidup sedenter (kurang gerak) dan nutrition transition yakni perubahan pola diet menjadi konsumsi makanan tinggi lemak, tinggi garam, tinggi glukosa, junk food dan fasfood (Popkin, Adair \& Ng, 2013).

Peningkatan prevalensi obesitas berbanding lurus dengan prevalensi penyakit penyerta (komorbid) yang ditimbulkan oleh obesitas seperti diabetes melitus, hipertensi, penyakit jantung, dislipidemia, kelainan saluran pencernaan, penyakit reproduksi
(Redinger, 2007). Obesitas menyebabkan disfungsi adiposit sehingga terjadi sekresi berbagain sitokin proinflamasi yang memicu berkembangnya resistensi insulin. Resistensi insulin akan menyebabkan penurunan utilisasi glukosa darah oleh sel dan jaringan sehingga terjadi peningkatan glukosa darah (hiperglikemia) yang dalam jangka panjang berkembang menjadi diabetes melitus (Segula, 2014).

Penelitian yang melibatkan laki-laki obesitas usia 18-49 tahun dengan jumlah sampel 11.075 menunjukkan bahwa $75 \%$ terdiagnosis diabetes melitus. Hal ini menunjukkan bahwa obesitas menjadi prediktor utama pada perkembangan penyakit diabetes melitus (Koelmeyer, Dharmage \& English, 2016). 4 pilar utama penanganan penyakit diabetes melitus berupa edukasi, perencanaan makanan, aktivitas fisik dan intervensi farmakologi (Putra \& Berawi 2015).

Aktivitas fisik merupakan setiap gerakan tubuh oleh otot rangka yang memerlukan pengeluaran energi. Penelitian menunjukkan bahwa orang dewasa sehat berusia 28 hingga 65 tahun memerlukan 
aktivitas fisik intensitas sedang selama minimal 30 menit apada 5 hari setiap minggu untuk meningkatkan dan menjaga kesehatan (Haskel, Lee, Pate, Powell \& Blair, 2007). Penelitian lain menunjukkan bahwa 1 kali melakukan aktivitas fisik itensitas sedang dapat meningkatkan ambilan glukosa sebesar 40\% (Venkatasamy, Pericherla, Manthuruthil, Mishra \& Hanno, 2013). Aktivitas fisik intensitas sedang yang umumnya dengan berjalan cepat selama 30 menit atau setara dengan $55-70 \%$ denyut nadi maksimal (Haskel, Lee, Pate, Powell \& Blair, 2007).

Penelitian Herwanto dkk pada tahun 2016 menunjukkan bahwa aktivitas fisik berlari memberikan efek bermakna terhadap kadar glukosa darah pada pria dewasa (Herwanto, Lintong \& Rumampuk, 2016). Aktivitas fisik intensitas sedang dapat meningkatkan sensitivitas reseptor insulin sehignga meningkatkan utilisasi penggunakan glukosa oleh sel, jaringan dan otot. Efek langsung terhadap glukosa darah dapat dilihat pada 2-72 jam setelah melakukan aktivitas fisik intensitas sedang (Bird \& Hawley, 2017). Hal ini terjadi karena serapan glukosa tetap meningkat hingga 120 menit setelah aktivitas fisik intensitas sedang karena peningkatan glucose transporter (GLUT) 4 di memberan plasma dan tulubus $\mathrm{T}$ (Borgouts \& Keizer, 2000).

Berdasarkan uraian di atas, peneliti tertarik untuk mengetahui pengaruh aktivitas fisik intensitas sedang terhadap kadar glukosa darah sewaktu dan mengetahui rerata penurunan glukosa darah sewaktu setelah melakukan 1 kali aktivitas fisik intensitas sedang pada laki-laki obesitas di Fakultas Kedokteran Universitas Lampung.

\section{METODE}

Penelitian ini merupakan jenis analitik komparatif numerik berpasangan dengan desain quasi eksperimental dan metode pengambilan data dengan pengukuran berulang (pre test-post test design) dengan kelompok kontrol. Sampel yang digunakan dalam penelitian ini berdasarkan rumus hitung numerik berpasangan sebanyak 30 subjek yang terdiri atas 20 orang obesitas grade II atau indeks masa tubuh (IMT) $\geq 30$ $\mathrm{kg} / \mathrm{m}^{2}$ dan 10 orang dengan IMT normal yaitu $18,55-22,99 \mathrm{~kg} / \mathrm{m}^{2}$.

Penelitian terbagi dalam 3 kelompok yaitu kelompok kontrol negatif (K1) terdiri atas 10 orang obesitas grade II yang tidak diberikan intervensi, kelompok kontrol positif (K2) terdiri atas 10 orang dengan IMT normal yang tidak diberikan intervensi dan kelompok perlakuan $(\mathrm{P})$ terdiri atas 10 orang obesitas grade II yang diberikan aktivitas fisik intensitas sedang berupa berjalan cepat selama 30 menit. Pemeriksaan glukosa darah pretest dilakukan pada seluruh kelompok sebelum diberikan intervensi sedangkan posttest dilakukan pada menit ke 120 setelah kelompok intervensi melakukan aktivitas fisik intensitas sedang berupa berjalan cepat selama 30 menit.

Pengolahan dan analisis data dengan menggunakan perangkat lunak komputer. Uji normalitas menggunakan Shapiro Wilk karena total sampel kurang dari 50 subjek. Uji bivariat dilakukan menggunakan Paired $T$ Test untuk mengetahui perbedaan rerata pretest dan posttes kemudian dilanjutkan dengan One Way Anova untuk mengetahui perbedaan rerata pada masing-masing kelompok.

HASIL

\section{Analisis Univariat}

Tabel 1: Distribusi Rerata Kadar Glukosa Darah pretest dan posttest

\begin{tabular}{ccc}
\hline \multirow{2}{*}{ Kelompok } & \multicolumn{2}{c}{ Rerata $(\mathrm{mg} / \mathrm{dL})$} \\
\cline { 2 - 3 } & Pretest & Posttest \\
\hline K1 & 95,3 & 91,6 \\
K2 & 94,2 & 85,9 \\
P & 96,4 & 76,8 \\
\hline
\end{tabular}

Tabel di atas menunjukkan hasil rerata pretest dan posttest glukosa darah sewaktu (GDS) pada masing-masing kelompok, dimana penurunan terbesar terjadi pada kelompok perlakuan (P) sebesar 19,6 mg/dL. 
Tabel 2: Distribusi Uji Normalitas Data menggunakan Uji Shapiro Wilk

\begin{tabular}{ccc}
\hline Kelompok & \multicolumn{2}{c}{ Nilai P } \\
\cline { 2 - 3 } & Pretest & Posttest \\
\hline K1 &, 526 &, 289 \\
K2 &, 083 &, 646 \\
P &, $054^{*}$ &, 095 \\
\hline
\end{tabular}

*transformasi data dengan sqrt

Berdasarkan tabel di atas data pada kelompok K1 dan K2 terdistribusi normal dengan nilai $\mathrm{p}>0,05$. Pada kelompok $\mathrm{P}$, data posttest terdistribusi normal sedangkan data pretest tidak terdistribusi normal sehingga dilakukan transformasi menggunakan sqrt dan didapatkan nilai $\mathrm{p}=, 054$ dari angka semula yaitu $\mathrm{p}=, 042$. Dapat disimpulkan bahwa seluruh data sudah terdistribusi normal.

\section{Analisis Bivariat}

Tabel 3: Distribusi Perbedaan Rerata pada Kelompok K1, K2 dan P

\begin{tabular}{cccc}
\hline Kelompok & $\mathrm{n}$ & Selisih $(\mathrm{mg} / \mathrm{dL})$ & Nilai $\mathrm{p}$ \\
\hline $\mathrm{K} 1$ & 10 & 3,7 &, 087 \\
$\mathrm{~K} 2$ & 10 & 8,3 &, 058 \\
$\mathrm{P}$ & 10 & 29,6 &, 000 \\
\hline
\end{tabular}

Paired T Test dilakukan untuk melihat apakah terdapat perbedaan rerata nilai GDS pretest dan posttest. Kelompok K1 DAN K2 menunjukkan nilai $\mathrm{p}>0,05$ yang berarti menerima H0. Sehingga dapat disimpulkan bahwa tidak terdapat perbedaan bermakna secara statistik rerata nilai GDS pretest dan posttest pada kedua kelompok tersebut. Kelompok $\mathrm{P}$ menunjukkan nilai $\mathrm{p}<0,05$ yang berarti menolak H0. Dapat disimpukan bahwa terdapat perbedaan bermakna secara statistik rerata nilai GDS pretest dan posttest pada kelompok perlakuan.

Peneliti melakukan uji bivariat tambahan yaitu One Way Anova untuk mengetahui apakah terdapat perbedaan rerarat kadar GDS posttest pada masing masing kelompok. Tabel 5,6 dan 7 menunjukkan hasil uji homogenitas, One Way Anova dan Posthoc Bonferrani.
Tabel 4: Distribusi Uji Homogenitas

\begin{tabular}{cc}
\hline Uji Homogenitas & Nilai $\mathrm{p}$ \\
\hline Kadar GDS Posttest &, 529 \\
\hline
\end{tabular}

Nilai $p$ pada uji homogenitas data adalah $\mathrm{p}>0,05$ yaitu sebesar ,529. Dapat disimpulkan bahwa data kadar glukosa darah sewaktu posttest pada penelitian adalah homogen.

Tabel 5: Distribusi Uji One Way Anova

\begin{tabular}{ccc}
\hline One Way Anova & $\mathrm{n}$ & Nilai $\mathrm{p}$ \\
\hline $\begin{array}{c}\text { Kadar GDS } \\
\text { Posttest }\end{array}$ & 30 &, 003 \\
\hline
\end{tabular}

Nilai $\mathrm{p}$ didapatkan sebesar $\mathrm{p}=, 003$. Hal ini menunjukkan bahwa H0 ditolak karena nilai $\mathrm{p}<0,05$. Sehingga dapat disimpulkan bahwa terdapat perbedaan yang bermakna secara statistik kadar GDS pada masingmasing kelompok. Selanjutnya peneliti melanjutkan pada uji Posthoc Bonferroni untuk melihat secara spesifik kelompok mengalami perbedaan.

\section{Tabel 7: Distribusi Uji Posthoc Bonferroni}

\begin{tabular}{ccc}
\hline Kelompok & Kelompok & Nilai p \\
\hline K1 & K2 &, 474 \\
& $\mathrm{P}$ &, 002 \\
K2 & K1 &, 474 \\
& $\mathrm{P}$ &, 085 \\
$\mathrm{P}$ & $\mathrm{K} 1$ &, 002 \\
& $\mathrm{~K} 2$ &, 085 \\
\hline
\end{tabular}

Tabel di atas menunjukkan bahwa terdapat perbedaan rerata kadar GDS yang bermakna secara statistik pada kelompok K1 dan P. Hal ini dibuktikan dengan nilai $\mathrm{p}<0,05$. Sedangkan tidak terdapat perbedaan rerata kadar GDS yang bermakna secara statistik antara kelompok K1 dan K2 serta K2 dan P. Hal ini ditunjukkan dengan nilai $\mathrm{p}>0,05$.

\section{PEMBAHASAN}

Penelitian ini dilakukan untuk melihat pengaruh aktivitas fisik intensitas sedang 
terhadap penurunan kadar glukosa darah sewaktu pada laki-laki obesitas di Fakultas Kedokteran Universitas Lampung. kadar glukosa darah bertahan pada level tertentu sepanjang hari (70-150 mg/dL). Kadar tersebut biasanya berada pada level terendah pada pagi hari sebelum makan dan meningkat setelah makan (Sherwood, 2014). Kadar GDS seorang individu dengan spesimen darah kapiler dikatakan bukan diabetes jika nilai GDS <90mg/dL, belum tentu diabetes jika nilai GDS 90-199 dL, dan dikatakan diabetes melitus jika nilai GDS $\geq 200 \mathrm{mg} / \mathrm{dL}$ (Perkeni 2015)

Kelompok K1 yang terdiri atas 10 orang obesitas yang tidak diberikan intervensi didapatkan nilai pretest sebesar $95,4 \mathrm{mg} / \mathrm{dL}$ dan nilai posttest sebesar 91,6 mg/dL. Terjadi penurunan sebesar 3,7 mg/dL. Kadar tersebut masih dalam kisaran normal. Hal ini menunjukkan bahwa pada sampel obesitas, proses pengaturan fisiologis tubuh terhadap metabolisme glukosa masih baik. Obesitas dalam menyebabkan resistensi insulin membutuhkan waktu yang cukup lama. Tetapi obesitas dini akan meningkatkan risiko untuk terkena penyakit kronis saat dewasa (Koelmeyer, Dharmage \& English, 2016). Studi lanjutan Professional Health menunjukkan bahwa individu dengan IMT $\geq 35 \mathrm{~kg} / \mathrm{m}^{2}$ berisiko tinggi untuk mengalami diabetes melitus dibandingkan individu dengan IMT $<23 \mathrm{~kg} / \mathrm{m}^{2}$ (Segula, 2014).

Pemeriksaan kadar GDS pada kelompok K2 menunjukkan rerata GDS pretest sebesar $94,2 \mathrm{mg} / \mathrm{dL}$ dan posttest sebesar $85,9 \mathrm{mg} / \mathrm{dL}$. Terjadi penurunan sebesar $8,3 \mathrm{mg} / \mathrm{dL}$. Hal ini membuktikan bahwa pengaturan fisiologis yang melibatkan koordinasi antara insulin dan glukagon untuk mempertahankan keadaan normoglikemik pada orang normal terjadi dengan baik. Penurunan yang terjadi pada K1 dan K2 tidak bermakna secara statistik. Kelompok tersebut merupakan kelompok kontrol yang tidak diberikan intervensi. Sehingga tidak ada proses penggunaan glukosa sebagai sumber energi secara signifikan.

Kelompok P menunjukkan hasil pretest sebesar 96,4 md/dL dan posttest sebesar 76,8 $\mathrm{mg} / \mathrm{dL}$. Terjadi penurunan yang bermakna secara statistik yaitu sebesar sebesar $20,33 \%$ atau 19,6 mg/dL. Selama melakukan aktivitas fisik intensitas sedang, tubuh memerlukan energi berupa Adenosine Triphospate (ATP) yang berasal dari metabolisme glukosa. Glikogenolisis merupakan proses pemecahan simpanan energi cadangan glikogen dalam hati menjadi glukosa. Proses ini terjadi ketika kadar glukosa dalam darah tidak mampu memenuhi kebutuhan energi saat individu melakukan aktivitas fisik intensitas sedang.

Proses glikogenolisis yang terjadi pada setiap individu berbeda yaitu ada yang terjadi secara lambat dan cepat. Hal ini terjadi karena kebutuhan energi yang berbeda pula pada setiap individu. Perbedaan tersebut dipengaruhi oleh berbagai faktor seperti asupan makanan dan kebiasaan berolahraga. Seorang individu dengan asupan makanan tinggi glukosa sebelum beraktivitas, glikogenolisis akan terjadi secara lambat. Karena kadar glukosa dalam darah dapat memenuhi kebutuhan energi dalam beberapa waktu selama melakukan aktivitas fisik intensitas sedang. Kebiasaan berolahraga akan membuat tubuh seseorang tidak memerlukan energi lebih banyak ketika melakukan aktivitas fisik, sehingga proses glikogenolisis juga terjadi secara lambat. Proses glikogenolisis akan mempengaruhi kadar glukosa darah posttest yang diperiksa. Efek langsung aktivitas fisik intensitas sedang terhadap penurunan kadar glukosa darah sewaktu dapat dilihat pada 2-72 jam setelah beraktivitas. Tetapi dapat pula terjadi peningkatan kadar glukosa darah setelah beraktivitas. Hal ini terjadi karena proses glikogenolisis sedang berlangsung saat dilakukan pemeriksaan kadar GDS (Herwanto, Lintong \& Rumampuk, 2016).

\section{KESIMPULAN}

Aktivitas fisik intensitas sedang memiliki pengaruh bermakna secara statistik terhadap penurunan kadar glukosa darah sewaktu pada laki-laki obesitas di Fakultas Kedokteran Universitas Lampung. Rerata penurunan kadar glukosa darah sewaktu adalah sebesar $20,33 \%$ atau $19,6 \mathrm{mg} / \mathrm{dL}$ 
setelah 1 kali melakukan aktivitas fisik intensitas sedang.

\section{DAFTAR PUSTAKA}

Badan Penelitian dan Pengembangan Kesehatan. (2018). Riset Kesehatan Dasar (RISKESDAS). 1-384.

Bird, SR \& Hawley, JA. (2017). Update on the effects of physical activity on insulin sensitivity in human. BMJ Open Sport \& Exercise Medicine. 2(1): 1-26.

Borghouts, LB \& Keizer, HA. (2000). Exercise and insulin sensitivity: a review. Int J Sports Med. 21(1):1-12.

Ercho, NC., Berawi, KN., Susantiningsih, T. (2013). The relation of obesity with LDL and HDL levels at preclinic student of medical faculty of lampung university. Majority. 4(1) : 87-92.

Haskell, WL., Lee, IM., Pate RR., Powell KE., Blair SN., et al. (2007). Physical activity and public health: updated recommendation for adults from the American College of Sports Medicine and the American Heart Association. Med Sci Sports Exerc. 39(8):14231434.

Herwanto, ME., Lintong, F., Rumampuk, JF. (2016). Pengaruh aktivitas fisik terhadap kadar glukosa darah pada pria dewasa. Jurnal E-Biomedik. 4(1):156163.
Koelmeyer, RL., Dharmage, SC., English, (2016). DR. Diebetes in young adult men: social and health related correlates. BMC Public Health. 16(3): 64-90.

PERKENI. Konsensus pengendalian dan pencegahan diabetes melitus tipe 2 di Indonesia. 2015; Jakarta: PB PERKENI.

Popkin, BM., Adair, LS., Ng SW. (2012). Now and then: The global nutrition transition: the pandemic of obesity in developing countries. Nutr Rev. 70(1): 3-21.

Putra IWA, Berawi KN. (2015). Empat pilar penalatalaksanaan pasien diabetes melitus tipe 2. Majority. 4(9) : 8-12.

Redinger, RN. The pathophysiology of obesity and its clinical manifestations. Gastroenterology and Hepatology.2007; 3(11):856-863.

Segula, D. (2014). Complications of obesity in adults: a short review of the literature. Malawi Medical Journal. 26(1):20-4.

Sherwood, L. 2014. Fisiologi manusia : dari sel ke sistem edisi 8. EGC: Jakarta.

Venkatasamy, VV., Pericherla, S., Manthuruthil, S., Mishra, S., Hanno, R. (2013). Effect of physical activity on insulin resistance, inflammation and oxidative stress in diabetes melitus. $J$ Clin Diagn Res.7(8):1764-1766.

WHO. (2018). Obesity and Overweight. Geneva: WHO. 